\title{
HOLLY Cosmopolitan Global Justice: Brock v. the Feasibility Sceptic
}

[T] he basic idea behind feasibility scepticism is that whatever we may think about models of global justice...realizing the goals of global justice is so wildly unrealistic in practice that, at best, such models must remain as theorists' wishes about how the world should be (Brock, p. 325).

In Global Justice: A Cosmopolitan Account, Gillian Brock aims to provide 'workable' claims about the realization of global justice (p. vii), ${ }^{1}$ addressing 'concerns about implementation' (p. 4), and allowing us to move 'from theory to feasible public policy' (p. 4). She addresses two kinds of sceptic about the possibility of cosmopolitan global justice. The first kind of sceptic claims that we cannot do what the cosmopolitan claims we ought to do; the second kind of sceptic claims that we should not do what the cosmopolitan claims we ought to do. The second claim rests on the idea that doing what the cosmopolitan claims we ought to do would interfere with nationalism, and other goods like authentic democracy (see e.g. Ch. 1). In this comment on Brock's book, I will set aside the complaints of the second kind of sceptic - and in general normative questions about cosmopolitan global justice - and focus instead on the first kind of sceptic, and the associated descriptive claim that we cannot do what the cosmopolitan claims we ought to do. ${ }^{2}$

One might expect that in a book addressing sceptics about the feasibility of cosmopolitan global justice there would be some kind of criteria given for what a victory, or a defeat, might consist in. In other words, one might expect at least a sketch (and at most an explicit account) of the conditions under which a cosmopolitan proposal is to count as feasible. But Brock resists an explicit account, instead choosing (we may assume) to rely on a commonsense or pre-theoretical notion of feasibility. I take this to be problematic, mainly because I do not think there is a clear commonsense or pre-theoretical notion of feasibility. There are obvious candidate meanings, but none of these are consistent with philosophical usage. If all that is meant by 'feasibility' is some kind of formal possibility, let's say conceptual or metaphysical possibility, then almost every proposal political

1. This is following Thomas Nagel, 'The Problem of Global Justice', Philosophy and Public Affairs 33/2 (2005) 113-47. 2. Although, the claims of the two kinds of sceptics do overlap insofar as we ought to do only things that we can do. 
philosophers put on the table will come out as 'feasible'; from the anarchists' proposals through the communists', to the ideal theorists' various utopias. But the growing interest in and support for non-ideal theory shows that philosophers often want something more than formal possibility from a political theory; they want a theory whose recommendations could actually be implemented in the world as we find it.

But exchanging the term 'feasibility' for some other term, such as 'actual implementability', does nothing but shift the burden sideways. What philosophers seem to want when they ask that political theory be more practical is that its proposals tread the fine line between the acceptance of how things actually are, and the aspiration to change them without being wildly impractical. That fine line is not yet well-defined, and before it is defined, it can hardly be argued that any feasibility sceptic has been defeated.

Thus the aim of my comment will be to present an explicit concept of feasibility by which we might test cosmopolitan proposals for global justice, and to see how well this concept does in accommodating Brock's pre-theoretical notion of feasibility and the work it does in attempting to defeat one of the two kinds of sceptic she addresses. To that end, the paper will comprise three further sections. In the first, I will consider the argumentative strategies Brock employs against her opponents: the feasibility sceptics. In the second section, I will try to make Brock's ostensibly commonsensical notion of feasibility explicit, and argue that it is lacking in one crucial respect. I will argue that there is more to feasibility than Brock's discussion allows. In the third and final section, I will defend a concept of political feasibility that accommodates Brock's view but is arguably more philosophically useful, and stands a better chance of providing a clear victory against the feasibility sceptic.

\section{Brock's Argumentative Strategies}

Brock runs through a list of common complaints from the feasibility sceptic. Some complaints are epistemic - for example, that we cannot know when we are making progress toward a goal, that we do not know what works in trying to make such progress, or that we are not clear enough about what our goals are to even begin to answer such questions. Some are about people - for example, that it will be difficult to motivate people to make changes, or perhaps to create the institutions required to reach our goals. And some are about institutions - for example, that we do not have the institutions that we need now, and we might think that there is no realistic chance of expecting to have them in the near future.

Brock uses two main strategies in attempting to defeat the feasibility sceptic. The first strategy is to employ something like an a fortiori argument. She argues that 
certain things the feasibility sceptic claims to be infeasible are in fact actual. And from the stronger argument of actuality, one gets feasibility for free. The second strategy involves using something like an argument extrapolating from part to whole. A given proposal is feasible because part of it has already been achieved, or because it has been achieved on a smaller scale than it ideally requires. Let's look in a bit more detail at how these arguments work, and then in a subsequent section I will come back to comment on their effectiveness.

\section{Argument a fortiori: possible because actual}

In Chapter 8 ('Immigration'), Brock discusses the fact that a high proportion of migrant workers send money back to their families, in their home countries. These remittances have both positive and negative effects on the receiver countries. One effect which might be considered negative is that the remittance money is generally spent on daily consumables, rather then being used on public goods like health care, education, roads, and sanitation, a lack of which is the structural source of developing country poverty. As a solution to this problem, which is one obstacle to alleviating global poverty, Brock suggests that the countries employing migrant workers might compulsorily deduct a percentage of the workers' earnings to send back to their home country, and even better, the home country might match these funds 1:1 and use the raised money to provide public goods. Brock's evidence for thinking this kind of tax on remittances is feasible is that it is actual: it already happens in many cases of Filipino, Chinese, and Korean workers (p. 207).

In Chapter 5 ('Global Poverty, Taxation, and Global Justice'), Brock concentrates on global taxes that might be used to fund the relief of developing nation poverty. Much of the argumentation in this chapter also proceeds along the lines of 'possible-because-actual'. A global tax is feasible, she assumes, because we have already partial success in implementing one, e.g. air-ticket taxes (where a small fee is added to the sale of aeroplane tickets, which goes towards providing pharmaceuticals and malaria treatments in developing countries). Initially thirteen governments agreed to introduce air-ticket taxes, and now thirty-eight governments have implemented them (pp. 133-134). Or for another example, we have had success in implementing a tax on deep seabed mining, implemented via a United Nations' convention in the 1980 s and now signed by 158 countries (p. 131). Brock also comments that two popular proposals for a global tax, namely a currency transaction tax and a carbon tax, 'have achieved a small measure of implementation success' (p. 132). The carbon tax has been enacted in Sweden, Finland, Germany, the Netherlands and Norway; the currency transaction tax has attracted conditional commitment from Canada, Belgium and France (these countries have promised to enact the tax if there is support from the international community). 


\section{Argument by extrapolation from part to whole (progress)}

In Chapter 8, Brock discusses immigration and its relation to global justice. She argues that it is unclear whether the argument for open borders (based on a behind the veil preference for large-scale freedom of movement), or the argument for closed borders to protect cultural community, would prevail in ideal theory. Yet she also argues that it is rather clearer that in non-ideal theory, immigration poses a serious threat to those who are left behind (p. 191). She uses recruitment by developed countries of healthcare workers from developing countries as an example. This can lead to a dire shortage of healthcare workers, such as occurs in sub-Saharan Africa, with associated effects on the remaining population. Brock argues that a 'comprehensive solution' to this kind of problem involves the following:

(1) an international code that specifies uniform standards for both private and public sectors, and that applies to all countries in similar circumstances; (2) an international agency that oversees activities, brokers compensation, can punish violators (perhaps by levying meaningful fines), and so forth; (3) each country's aiming at and achieving self-sufficiency with respect to human resources in health care; and perhaps (4) addressing the seemingly insatiable demand for health care in developed countries (p. 202).

The assumption is that these components of a comprehensive solution are individually and jointly feasible, and Brock suggests that we have made progress towards justice in healthcare worker recruitment by pointing to the fact that 'there is already at least one version of an international code that could do the job outlined in (1) and several proposals concerning (2)' (p. 203, n. 41). She considers the World Health Organization, alone or in conjunction with another international organization, to be a good candidate for the job of (2).

As another example, in Chapter 7 ('Humanitarian Intervention'), Brock argues that there is progress toward the goal of having sovereign nations intervene with corrupt or human rights-abusing nations in order to restore justice to their citizens. This progress consists in the International Committee on Intervention and State Sovereignty (ICISS) having come up with clear guidelines for when an intervention is acceptable (pp. 181-184). Again, this is a partial progress. Clear guidelines upon acceptable humanitarian intervention are taken to be the first step in creating a just world order in which states intervene upon other states for humanitarian reasons.

\section{Comment on the argumentative strategies}

I have so far laid out two of the prominent argumentative strategies that Brock 
employs against feasibility sceptics. The first was an a fortiori argument; moving from the claim that something is actual to the weaker claim that it is feasible. The other was the argument by extrapolation from part to whole; moving from the claim that there is partial progress toward a goal in some area, to the conclusion that the goal itself is feasible. In this section I want to comment on what is missing in Brock's book by virtue of the fact that these are her primary approaches to defeating the feasibility sceptics.

Argument a fortiori is certainly a respectable argumentative strategy. But although the arguments are presented in this form, it remains to be seen whether that is their most plausible form. Let's return to the examples just canvassed. First, a remittance tax is not feasible internationally just because it is actual for some Korean, Chinese and Filipino workers. It is certainly feasible for some Korean, Chinese and Filipino workers because it is actual, but whether the tax scales up without problems is another question. The fact that the tax has had some success when implemented in certain employer-countries might be taken as evidence for the claim that it can be successful in other employer-countries, but before we could firmly commit to that we'd need to consider whether there were any features, say about the structure of other governments, that might prevent a successful instantiation of remittance taxes.

Second, the international agency Brock considered to be the best candidate for overseeing and sanctioning healthcare worker recruitment was the World Health Organization, alone or in conjunction with one or more of the International Organization for Migration, United Nations Development Programme, World Medical Association, and Council of International Organizations of Medical Societies. However, the ability to sanction violators is not something currently within the ability of any one of these organizations. Neither, in fact, is there any international agency with such power, except those to which member states have voluntarily submitted themselves (such as the International Criminal Court). The lack of international agencies capable of creating binding agreements and sanctioning agents in the event of violations of said agreements is one of the main obstacles to international cooperation in many different areas, and there is no reason to think (and in any case, Brockgives us no reason tothink) that this situation should be any different when it comes to enforcing rules of non-recruitment of healthcare workers in developing countries, or rules of compensating developing countries when such recruitment is undertaken.

This kind of issue is exactly what those who are optimistic about the realization of global justice and those who are sceptical about it disagree about - not whether there are some steps it would be merely possible to take, but whether there is anything that can be done that has any realistic chance of succeeding. A feasibility 
sceptic of the kind Brock takes herself to be addressing will not be placated by her suggestion that there are candidate agencies already in existence for overseeing healthcare worker recruitment, because those agencies cannot do what is perhaps the most important part of the comprehensive solution. This is another example of extrapolating from the fact that some apparent progress has been made the drafting of a code for acceptable healthcare worker recruitment - and the existence of an international agency that could oversee the process - which, granted, would be easy if everyone voluntarily complied - to the conclusion that the goal in question (global justice in healthcare), is feasible. But this seems like an unwarranted conclusion, for the same reasons mentioned above. The inability to hold states to their promises is likely the common mechanism that prevents many kinds of international agreements from being binding in practice.

At the end of Chapter 8, Brock considers a long list of potential 'win-win' situations where both immigrants' home countries and their host countries would benefit from a particular arrangement. These include: developed countries paying developing countries compensation at five times what it cost to train a health care worker who has been recruited; developed countries recruiting migrants for training purposes (i.e. making training into a commercial venture); sending immigrants from developing countries to low-population areas in developed countries to boost the economic well-being of those areas; and so on (pp. 208210). This kind of listing of things that countries 'could' do goes on throughout the book. While Brock is ostensibly trying to provide practical ways to solve particular problems for global justice, little attention is given to how likely it is that the proposals she outlines could be brought to pass, or how hard it might be to implement them, and only cursory attention is given to what the obstacles might be.

Both of her argumentative strategies amount to roughly the same thing, namely the conclusion that progress is good evidence of eventual success. Such reasoning is problematic, because it might just as well turn out that the features that make the first steps toward some goal feasible are exactly the features that make achieving the goal infeasible. An internationally-implemented luxury goods tax, or currency exchange tax, for example, is on a different scale and with a different scope to a thirty-eight government strong air-ticket tax. The fact that the carbon tax has success only among countries in the European Union (EU) might be because of a feature that makes it more likely to succeed within the EU and less likely to succeed internationally - the EU has a governing body that the wider global community does not.

Likewise, it is just as conceivable that coming up with guidelines on acceptable 
humanitarian intervention should count as progress toward the goal of actual acceptable interventions on humanitarian grounds as it is that it should end up illustrating more clearly that no real-world circumstances are likely to occur such that an intervention would count as acceptable. Just consider a parallel case: the fact that we can achieve relatively high levels of compliance with the state's laws in a modern democracy shouldn't be taken as progress towards realizing the goal of full compliance with the state's laws, nor as evidence that full compliance is something we can realistically hope for. There are circumstances in which partial success or progress can be taken as a sign that a goal is feasible, and circumstances in which it would be crazy to draw that conclusion.

\section{A pathways account of feasibility?}

[T] he case against the feasibility sceptic builds - there are clear steps we can take (and, in some cases, are taking) towards better realizing the goals of global justice (p. 172).

In this section I return to try to make Brock's commonsense or pre-theoretical account of feasibility explicit, so that I might consider its shortcomings. I will suggest that feasibility is a richer concept than Brock allows for, and that she concentrates on one element of the concept at the exclusion of other important elements. A richer notion of feasibility of course means more scope for the attacks of the feasibility sceptic (because if a proposal has to meet more criteria to count as feasible, it will be harder for it to count as feasible than if it had only to meet one criterion, especially if that is only a relaxed criterion), but it also means a cleaner victory for the person who would defend cosmopolitan global justice against those who are sceptical about its feasibility.

In order to demonstrate that Brock's concept of feasibility (and let me restate that she does not give an explicit account, so one must deduce her concept from her usage) is narrower than it usefully could be, allow me to digress with what is an apparent problem for her usage. It seems safe to say that Brock's emphasis in the book is on transition. In the passage cited above, she talks about the 'clear steps we can take' to realize a particular goal. Much of her book is concerned to illuminate a path from $a$ to $b$, where $a$ is the current state of the world and $b$ is some state of the world in which there is institutional reform leading to a greater degree of cosmopolitan justice. By proving that there is a way to get from here to there, Brock hopes to eliminate concerns that the goal is infeasible, answering the sceptic who might have claimed that the goal is impossible in virtue of there being no way to bring it about.

Let's state this commonsense or pre-theoretical account of feasibility-astransitionability more clearly as: 
1) a political proposal $p$ is feasible if and only if there are individual steps we can take which together realize it.

The question to ask, of course, is whether this concept of feasibility is a good one. I think that whether there is a path from the current to the proposed state of affairs is an important consideration in figuring out whether a political proposal is feasible, but it is one important consideration among many. The obvious problem with taking it to be the only important consideration is that any one step in a collection of steps necessary to realize a certain end might itself be easily performed, without it being the case that the collection of steps necessary to realize a certain end taken together can be easily performed. To bring this intuition out more clearly, consider a complicated military strategy. It might easily be that each of the steps in an attack is individually feasible. It might be that each individual involved in the plan knows his or her part. And it might be that all the required machinery and communications are running without problems. Still, we know from experience that anything can happen, and that the longer and more complicated a plan, the more likely it is that something will go wrong, or at least, not according to plan. The probability of $a, b$, and $c$ is the probability of $a$ multiplied by the probability of $b$ multiplied by the probability of $c$. So while the probability of the conjuncts $a, b$, and $c$ might each be e.g. 0.8 , the probability of the conjunction $a, b, c$ will be roughly 0.5 .

What is important to feasibility, then, is not only whether some pathway from $a$ to $b$ exists, but whether the chance of that pathway leading to the goal, given that we choose to take it, is considered high enough (how feasible it is will have to be traded off against how desirable the goal is, and what risks accompany each of the steps along the way). That means giving up any simple binary notion of feasibility (i.e. in which 'feasible' and 'infeasible' are structurally the same as 'possible' and 'impossible') in favour of an account in terms of conditional probabilities. Cosmopolitan global justice of the kind Brock endorses is not either feasible or infeasible; it is more or less feasible depending on a wide range of considerations, which include transitional considerations but are not limited to them.

This short digression was designed to illustrate that the notion of feasibility Brock works with in her book is perhaps too safe. It stays with the simple cases where feasibility seems to be binary rather than concentrating on the difficult cases where feasibility is more clearly graded. It also sticks closely to an understanding of feasibility as transitionability (the idea that there are steps we could take to bring about a certain outcome), which neglects the importance of asking how likely the steps are to produce the outcome, and also neglects several other considerations which make for a richer notion of feasibility. In the next section, I will present a broader, and I argue more philosophically useful, concept 
of feasibility which accommodates Brock's implicit account but allows much less scope for disagreement about whether something is or is not feasible (and thus will fare more decisively against a critic).

\section{In defence of a broader notion of feasibility}

I mentioned in the last section that while transition is one important component of something's being feasible, it is not the only important component. Pablo Gilabert and I argue that feasibility is a package made up of stability, accessibility and cost analyses, calculated probabilistically. In this section I will briefly rehearse those arguments. ${ }^{3}$

In the opening section of this paper, I said that the obvious candidate meanings of feasibility, such as conceptual or metaphysical possibility, were too weak to be philosophically useful. While these are too weak to be of particular interest, they are certainly constraints upon the feasibility of a theory, which is to say, a theory must be possible in these ways to count as feasible, but it will need to be more on top of that. Thus we need a division between hard and soft constraints upon feasibility.

Hard constraints are of the kind just mentioned (e.g. conceptual possibility) that must be met for a theory to even be considered a candidate for feasibility. Soft constraints are constraints that can change over time, which makes room for the idea that something might be infeasible now without its being infeasible indefinitely. The temporary lack of governance in a state might be a soft constraint on its making a treaty with another state, but it is not a hard constraint because when government is restored such a treaty may easily be entered into. Culture is a soft constraint, because while strong cultures can make certain kinds of practices infeasible now (e.g. equality between men and women, secularism in schools) they might eventually be weakened in a way that allows change along these dimensions. Soft constraints are dynamic in a way that hard constraints are not. ${ }^{4}$

We argue that while stability is not necessarily a conceptual feature of feasibility, it is unlikely that any useful notion of feasibility would classify a fleeting realization of a goal as the realization of the goal being feasible. Something about what we mean when we say that a goal or proposed state of affairs is feasible (or one of its

3. A more detailed account of feasibility is offered in Pablo Gilabert and Holly Lawford-Smith, 'Political Feasibility: A Conceptual Exploration' Political Studies (forthcoming); and Holly Lawford-Smith, 'Understanding Political Feasibility' (manuscript).

4. If we only asked about a particular time slice, we might then categorize everything as a hard constraint. For example, if we only wanted to know whether it is possible to have a democratic election in the Democratic Republic of the Congo now we might be inclined to take the political turmoil there as a hard constraint rather than a soft one, even though if we took a wider temporal view we would do better to take it as a soft constraint. This is just to acknowledge that it matters for feasibility which time scales are being asked about. This separation between hard and soft constraints is similar to the distinction Mark Jensen makes between static and dynamic constraints (see Mark Jensen, 'The Limits of Practical Possibility', Journal of Political Philosophy 17/2 (2009) 168-184). 
synonyms) implies that the goal or proposed state of affairs must be stable when it is reached. Thus stability is an important aspect of feasibility. Another important feature is the assessment of costs, not limited to financial costs. If a proposal requires more than the available resources (time, effort, money, cooperation) it will be infeasible; and the closer it comes to using all of the available resources, the less feasible it will be. The analysis of costs explicitly does not include moral costs; we need to keep feasibility and desirability strictly separate, given the fact that some things which are highly immoral or undesirable are nonetheless feasible. That is to say, whether things can be done is one question, and whether things should be done, is quite another question; one that requires judgement about the kind of world we are in and the kind of world we want to be in.

One final element of our analysis of feasibility is the epistemic element. This is important because it acknowledges that there is a gap between what is feasible and what is (or can be) known to be feasible. Strictly, the philosophical concept of feasibility should capture all the things in the world that actually are feasible; but practically, because we are interested in a concept that will be of service to political philosophers, the concept should merely capture all those things that are feasible to the best of our knowledge. Even this last qualification needs to be qualified, because 'to the best of our knowledge' isn't much if we are uneducated and uninterested. We propose something like the following: an action is infeasible if it violates hard constraints; and an action is more feasible the more that an agent is likely to succeed in doing it, given that she tries (and we calculate this conditional likelihood by looking at how compatible an action is with the various soft constraints).

The 'given that she tries' part of the analysis is designed to rule out cases where an individual could easily do something, but doesn't want to or can't be bothered, from coming out as infeasible. If a person has ten dollars in her pocket and no pressing items to buy, then it is feasible for her to give it to a homeless person who asks for money. It is feasible for her to do so whether she wants to do so or not, and whether she is likely to do so or not. The same is true for collective agents. Solving global poverty is more feasible the more that the global community is likely to succeed in solving it, given that they try. But knowing what is feasible doesn't tell us what is likely. Brock comments in Chapter 5 while discussing a currency transaction tax, that it is hard to believe we could not collect the tax effectively from such countries if the will was mobilized to do so' (p. 133). But whether we can mobilize the will, and whether we can thereby expect trying, is a further question, a question which demonstrates the difference between what is feasible and what is likely. We argue that useful answers to feasibility questions depend on assuming the trying of the right kinds of agents. For example, if we 
have no reason to expect the global community to try to alleviate poverty, we might instead ask about what we could do if we tried, for some salient 'we', such as the group of willing nations.

This more nuanced concept of political feasibility accommodates Brock's implicit usage (transitionability and accessibility are pretty much the same thing), but also extends it in a way that is more philosophically useful, allowing us to rule out as infeasible pathways that are a package of individually feasible yet jointly infeasible steps, and taking into account that to be feasible a proposal must not violate certain kinds of constraints, and must be known not to violate them. The fact that this concept of feasibility is richer than the one Brock seems to be working with means the feasibility sceptic might have more to say against the defender of cosmopolitan global justice, but means also that the defender of cosmopolitan global justice has more resources to respond, because she will be able to see more clearly where the sceptics' criticisms are directed, and thus how better to answer them.

\section{Summary and Comments}

In my view, a political proposal is feasible when it does not violate hard constraints, and more feasible than another the more compatible it is with the various soft constraints. I should acknowledge that the proposal in the previous section is hardly the end of the matter. It has its own set of problems to overcome; perhaps in the end feasibility will turn out to be the kind of thing that has more than one sense, a feature which, if true, might explain why there is so much disagreement between philosophers about which things are feasible (non-ideal) and which are not (ideal, utopian etc.). In other words, for any given occurrence of the term 'feasible' or one of its synonyms, a person might mean any one or more of, for example, psychological, political and institutional feasibility, at the very least. ${ }^{5}$

Some particular political proposal might be institutionally feasible because the institutions and mechanisms required to implement it are in place, but fail to be psychologically feasible because there's not a way we can bring people to act in a way that is consistent with its institutional implementation. Or a proposal might be politically feasible because the political system allows it, but not institutionally feasible because no institution could implement it, and so on. Furthermore, one might be tempted to think that political and institutional senses of feasibility will be much less controversial and much easier to establish, while the psychological sense will long remain controversial and elusive. That is, because psychology is to a large degree plastic, it is hard to get a clear picture on what people can

5. I am grateful to Gillian Brock for discussion on these points. 
be motivated to do, or what it is reasonable to expect from them. What people can be motivated to do and what it is reasonable to expect from them depends a lot on the kinds of environments they grow up in, and the kinds of incentive/ disincentive structures we can afford to (or are willing to) put in place. Because people generally take as normal what they are habituated to, we can to a large extent change people by changing environments. But much remains to be seen in what the limits to that kind of change are, and whether such large scale social engineering is itself feasible, or desirable.

Holly Lawford-Smith

Australian National University

holly.lawford-smith@anu.edu.au

\section{the globaljusticenetwork}

